11 | 2007

Varia

\title{
Les programmes collectifs
}

\section{Christian Sapin}

\section{(2) OpenEdition}

\section{Journals}

Édition électronique

URL : https://journals.openedition.org/cem/2012

DOI : $10.4000 /$ cem. 2012

ISSN : 1954-3093

Éditeur

Centre d'études médiévales Saint-Germain d'Auxerre

Édition imprimée

Date de publication : 15 août 2007

ISSN : 1623-5770

Référence électronique

Christian Sapin, «Les programmes collectifs », Bulletin du centre d'études médiévales d'Auxerre I BUCEMA [En ligne], 11 | 2007, mis en ligne le 28 août 2007, consulté le 22 septembre 2022. URL : http://journals.openedition.org/cem/2012 ; DOI : https://doi.org/10.4000/cem.2012

Ce document a été généré automatiquement le 22 septembre 2022.

\section{(c) (i) (2)(2)}

Creative Commons - Attribution - Pas d'Utilisation Commerciale - Partage dans les Mêmes Conditions 4.0 International - CC BY-NC-SA 4.0

https://creativecommons.org/licenses/by-nc-sa/4.0/ 


\title{
Les programmes collectifs
}

\author{
Christian Sapin
}

Le PCR « Matériaux de construction et critères de datation autour de l'an mil dans les régions Bourgogne, Centre, Pays-de-la-Loire »

1 Les rencontres de 2006 ont été marquées par trois réunions sur sites autour des thèmes :

- supports et appareils (Orléans, en mars) ;

- maçonneries des églises et châteaux de Bourgogne des $\mathrm{X}^{\mathrm{e}}-\mathrm{XI}^{\mathrm{e}}$ siècles (autour de Tournus, Brancion, Cluny, en mai), et

- les comparaisons avec la même thématique en Touraine (Langeais, Loches, Tours, en octobre).

2 Ces rencontres de travail ont donné lieu à des comptes rendus détaillés dans le rapport annuel. Parallèlement, les travaux thématiques, les sites monographiques et les fiches d'enregistrement des données ont été poursuivis. Une réflexion a été amorcée sur la création d'une base de données et elle sera poursuivie pour sa création, en 2007, en fonction des disponibilités et des rapprochements avec la base Monument d'ARTeHIS UMR 5594 et du BRGM, en cours de construction et en cours de tests, par Stéphane Büttner. À partir des notices, une synthèse de tous les thèmes traités ou abordés sera élaborée (apport de l'archéométrie croisé avec les traces de tailles, les appareils, les typologies d'ouverture, les sols, les charpentes, les diversités régionales...) par l'ensemble des participants pour une publication.

Le GDRE CNRS « Terre cuites architecturale et nouvelles méthodes de datation » (Maylis Baylé, Pierre Guibert, Philippe Lanos et Christian Sapin)

Programme en cours - édifices étudiés en 2006 :

Notre-Dame-sous-Terre, Le Mont-Saint-Michel ${ }^{1}$

4 Les analyses ont confirmé et précisé l'étude de bâti faite en 2003-2004 par le Centre d'études médiévale d'Auxerre. L'ensemble des 14 échantillons de brique prélevés par l'équipe de Bordeaux a été traité par thermoluminescence (TL). Des datations radiocarbone ont été obtenues par Lyon à partir des charbons extraits des mortiers. L'étude archéomagnétique (Laboratoire de Rennes) est également achevée. Les 
datations par thermoluminescence montrent pour l'ensemble des maçonneries testées que la production des briques a eu lieu dans le courant du $\mathrm{X}^{\mathrm{e}}$ siècle, à l'exception d'un échantillon prélevé dans la galerie supérieure dont la date significativement plus ancienne que les treize autres pourrait être l'indice d'un remploi d'un matériau confectionné environ deux siècles plus tôt. La partition des échantillons en deux ensembles appartenant aux deux phases de construction mises en évidence par les études archéologiques et architecturales permet de proposer des âges moyens pour la production des briques :

5 Les dates TL moyennes se séparent chronologiquement dans le sens conforme à l'étude architecturale, avec une probabilité très voisine de $80 \%$ (on ne tient compte pour cette analyse que des incertitudes statistiques, car elles représentent correctement la dispersion des dates). Un calcul statistique à partir du logiciel RenDate (Lanos et Dufresne, Rennes) indique que les deux phases de construction se sont succédé en moins d'une centaine d'années avec une probabilité de $95 \%$. Les datations radiocarbone des maçonneries sont en général concordantes avec les datations TL des briques, à l'exception de la fenêtre 65 (Lyon-2377) pour laquelle une plus grande ancienneté du charbon est attestée par rapport à la TL, d'une part, et par rapport aux autres charbons des maçonneries de la même phase architecturale, d'autre part. Cet écart de 100 à 200 années par rapport à l'âge de cuisson des briques peut s'expliquer par un effet "vieux bois» particulièrement visible pour cet échantillon. La comparaison des séries de dates montre globalement une tendance à des âges radiocarbone plus élevés que la $\mathrm{TL}$, les recouvrements se situant au $\mathrm{X}^{\mathrm{e}}$ siècle.

6 Les datations effectuées dans les parties romanes sont très significativement plus tardives : elles recouvrent le $\mathrm{XI}^{\mathrm{e}}$ et la première moitié du XII ${ }^{\mathrm{e}}$ siècle.

7 L'étude archéomagnétique a montré l'absence de positions de cuisson cohérentes des briques par rapport au champ magnétique terrestre (CMT), dans l'hypothèse de briques cuites à une même période, ce qui a empêché la datation à partir de l'inclinaison du CMT. Cependant, des informations d'ordre technologique ont été obtenues grâce à cette étude multidisciplinaire. L'hypothèse d'un incendie ayant été exclue, après analyse du signal archéomagnétique des briques (pas d'aimantations secondaires détectées lors des désaimantations thermiques au laboratoire) et étude TL d'échantillons de mortiers, il restait la possibilité d'une cuisson sans ordonnancement particulier. Les reconstructions de position de cuisson des briques en prenant comme direction du champ magnétique celle correspondant aux dates TL des maçonneries, indique qu'une cuisson en meule a fort probablement été réalisée, ce qui correspondrait à de petites productions de matériau.

Vieux-Pont-en-Auge

8 Six échantillons ont été prélevés à Vieux-Pont. Trois d'entre eux proviennent de deux briques du mur sud de la nef, deux autres de deux briques du mur sud du clocher, et un du mur nord de la nef. Les datations par TL et OSL (luminescence optiquement stimulée) ont été réalisées sur les échantillons du mur sud de la nef et du clocher. L'un d'entre eux n'a pu être daté, Bdx 9627, en raison d'un manque de matière. L'échantillon du mur nord, Bdx 9629 est en cours d'étude au moment où nous écrivons ces lignes.

Ouilly-le-Vicomte

9 Trois échantillons de brique provenant des maçonneries du mur sud et d'un contrefort nord ont été échantillonnés. Pour le mur sud, les deux éléments, isolés dans un appareillage de pierres calcaires appartiennent à une zone de réfection située sous une 
fenêtre de la nef. L'étude de caractérisation pétrographique et élémentaire de ces briques a montré leur diversité de composition que l'on peut interpréter comme une diversité de matière première. Cela contraste avec Vieux-Pont, édifice pour lequel les briques du mur sud montraient une bonne homogénéité de composition. Les datations par TL effectuées sur les deux échantillons sud à partir des petites inclusions de quartz (3-12 $\mu \mathrm{m})$ montrent qu'il s'agit de matériaux mis en œuvre au cours de phases de restauration ou de modification $d u \mathrm{XV}^{\mathrm{e}}$ siècle pour l'une, de la première moitié du XVIII siècle pour l'autre. Le troisième échantillon, prélevé sur le contrefort nord, est en cours d'étude actuellement.

10 Autres sites en cours pour la Normandie : donjon d'Avranches, évêché de Lisieux, Rugles, Vieux-Pont-Saint-Aubin...

\section{NOTES}

1. L'ensemble des contributions aux recherches sur ce site sera prochainement publié.

\section{INDEX}

Index géographique : France/Le Mont-Saint-Michel, France/Ouilly-le-Vicomte, France/Vieux-

Pont-en-Auge 